\title{
Clarification of Psychological Symptoms by Orthopaedic Expert Witness: Outcome of Ten Cases
}

\author{
Koch $\mathrm{HCH}^{1 *}$, Mackinnon J ${ }^{2}$ and Helen Beesley ${ }^{3}$ \\ ${ }^{1}$ Chartered Psychologist Cheltenham and Gloucester Nuffield Hospital, Hugh Koch Associates, UK \\ ${ }^{2}$ Consultant Orthopaedic Surgeon, Cheltenham and Gloucester Nuffield Hospital, UK \\ ${ }^{3}$ Chartered Psychologist, Hugh Koch Associates, UK
}

Submission: April 25, 2017; Published: July 17, 2017

*Corresponding author: Koch HCH, Department of Chartered Psychologist Cheltenham and Gloucester Nuffield Hospital, UK and Hugh Koch Associates, Cheltenham and London, UK, Email: hugh@hughkochassociates.co.uk

Abstract

The orthopaedic expert witness is frequently faced with one or more psychological symptoms during a typical personal injury interview. This paper describes the common psychological symptoms presented by either adults or children. It highlights the benefits arising from an early recommendation in the orthopaedic report for a further report from a psychologist.

\section{Introduction}

Providing an Orthopaedic opinion as an expert witness in a civil claim is a complex role. Notwithstanding the myriad of physical factors that need to be considered with the appropriate supporting records and scans, the orthopaedic expert will also be cognizant of other symptoms, including psychological and social signs. Although these will be largely outside his/ her competence and training, orthopaedics expert will be minded to make reference to these if only to recommend a full, comprehensive psychological assessment be commissioned.
This paper illustrates the types of symptoms to consider including in the general questioning of a claimant in a personal injury case for a road traffic collision (RTC).

\section{Short Communication}

The first author reviewed the most recent ten cases he had assessed in his medico-legal orthopaedic clinic to identify the several psychological symptoms which required mentioning.

Table 1

Table 1: Psychological Symptoms Identified in Five Orthopaedic Adult RTC Cases

1. Presentation: Abnormal speech (slow, unusual content); Tearful: highly anxious; excessive anger. Abnormal verbal/nonverbal pain expression.

2. Pre-index Accident History: Previous Trauma (including similar to index event) Recent adverse events (in past year) e.g. bereavement redundancy, divorce; abnormal alcohol or drug use; psychotropic medication.

3. Immediate post-accident: experience of near-death; excessive fear; sleep disturbance (nightmares); avoidance of travel; irritability tearfulness and low mood.

4. Next 12 months: Other adverse life events (e.g. bereavement, redundancy, divorce); travel anxiety (driver, passenger, pedestrian) Social difficulties (relationship; inactivity; lack of contact with others); impaired concentration/memory.

5. GP attendance for psychological difficulties (antidepressant medication; counselling)

6. Recurrent psychological problems 'Now' (at time of interview).

7. Self report need for psychological help. 
Table 2

Table 2: Psychological Symptoms Identified in Five Orthopaedic Paediatric RTC Cases

1. Presentation: Over-attachment to parent; excessive anxiety or tearfulness.

2. Pre-index Accident History: Previous attendance at GP for emotional problems; previous similar accident; parental separation and bereavement; sleep disturbance; bedwetting.

3. Immediate post-accident: Excessive fear; sleep disturbance (nightmares); reluctance to travel; tearfulness.

4. Next 12 months: Other adverse life events; travel anxiety (as passenger); school referral/ avoidance/problems, impaired concentration.

5. GP attendance for psychological difficulties (counselling; CAMHS)

6. Recurrent psychological problems 'Now' (at time of interview).

7. Parental expectation of need for psychological help.

(Table $1 \& 2$ ) below indicate the commonest type of psychological symptoms that the orthopaedic expert is likely hear or elicit during the orthopaedic assessment.

It is not possible or appropriate for the orthopaedic expert to establish in a detailed or psychologically valid way the extent, severity or overview of every one of these items. However, it is helpful to claimant, lawyer and the court to identify at the earliest possible stage whether a recommendation for a full psychological assessment in warranted. This can have the following benefits:

1. Early psychological assessment.

2. Early advice or treatment recommendation.

3. As a result of $[1,2]$ the prognosis can improve i.e. shorter duration of symptoms; less entrenched or habitual behaviours (e.g. travel avoidance).

4. Reduction of work - related disability due to psychological factors.

One additional area worthy of mention is that of chronic pain. The orthopaedic expert may identify non-verbal, verbal and motivational issues in relation to the claimant's chronic pain. He may/may not diagnosis an orthopaedic/physical disorder but the accompanying functional overlay may will point to a pain disorder/somatic symptom disorder with associated psychological factors and hence a further report from a psychologist with a special interest in chronic pain can be recommended.

In each particular legal case, a lawyer and administrator, plus a medical advisor if available, would review the orthopaedic expert's comments and decide if the recommendation for a further psychological/psychiatric assessment was appropriate and warranted. Typically, a recommendation of this type would be accepted and expedited.

\section{Conclusion}

This short paper should be of interest to all orthopaedic expert witnesses and highlights the types of psychological symptoms or behaviours that will be beneficial to note and flag up in the orthopaedic interview, some of which can usefully be included in the orthopaedic report with a recommendation for a psychological report. These symptoms can then be rigorously assessed by a psychologist in term of diagnosis, attribution and prognosis.

\section{References}

1. (2016) Legal mind: Contemporary Issues in psychological Injury and law. In: Koch HCH (Ed.), Expert witness publications, UK.

2. Koch HCH, Cleary A, Mackinnon J, Willows (2017) Chronic pain and understanding the Interplay between orthopaedic and psychological aspects: A case study. MOJ Public Health 5(6).

\section{Your next submission with Juniper Publishers will reach you the below assets}

- Quality Editorial service

- Swift Peer Review

- Reprints availability

- E-prints Service

- Manuscript Podcast for convenient understanding

- Global attainment for your research

- Manuscript accessibility in different formats

( Pdf, E-pub, Full Text, Audio)

- Unceasing customer service

Track the below URL for one-step submission https://juniperpublishers.com/online-submission.php 